\title{
A Review on Instructing English through Literary Genre
}

\author{
Nadia HAMIMED \\ Department of Civil Engineering, \\ Faculty of Technology, University of Abou Bekr Belkaid \\ Tlemcen, Algeria \\ Email: nadia.anglais@yahoo.fr
}

Received: 6/29/2021 Accepted: 8/17/2021 Published:9/24/2021

\begin{abstract}
This study aims to highlight the utilization of literary genre as a well-liked method for instructing both language skills (that is to say, writing, reading, speaking, and listening) and language fields (that are grammar, pronunciation, and vocabulary). Why employing literary textbooks in foreign language classrooms and the main motives for choosing appropriate fictional texts in these classrooms are emphasized to make the reader acquainted with the motivating incentives and standards for foreign language teachers' employing and picking erudite textbooks. Additionally, the teaching of language skills and literary genre gains benefits of diverse fields of literature (like drama, poems, tragedy and tales) to language teaching and to several difficulties met by language teachers in the sphere of instructing English using fiction (i.e. shortage of training in the field of literature teaching English as a Second English and Teaching English as a Foreign Language curriculums, deficiency of precise aims describing the function of fiction in English as a Foreign Language and English as a Second Language, foreign language teachers' not possessing the experience and preparation in literature, and lack of suitable teaching tools to be utilized by foreign language teachers in a class milieu) are taken into consideration.

Keywords: Literary genre, English as a Foreign Language, English as a Second Language, language skills, teaching literary work
\end{abstract}

Cite as: HAMIMED, N. (2021). A Review on Instructing English through Literary Genre . Arab World English Journal, 12 (3) 278-293.

DOI: https://dx.doi.org/10.24093/awej/vol12no3.19 


\section{Introduction}

In the latest time, the position of literature as a fundamental element and basis of authenticated textbooks of the language program instead of an eventual goal of English teaching has been obtaining impetus. Amongst language teachers, there has been an intense examination regarding where, why, and how literature ought to be integrated into TEFL and TESL programs. The lively debate of how literature and TEFL / TESL training can operate jointly and cooperate for the profit of learners and instructors has guided the development of motivating brainstorm and enhanced teaching for everyone. A lot of instructors believe that the utilization of the literary genre in language teaching is a motivating and creditable matter (Sage, 1987). In this study, why a language instructor has to employ literary textbooks in TEFL and TESL, what kinds of bookish texts teachers should utilize with foreign language students, the teaching of the language skills and literary genre, and the benefits of diverse types of literature to TEFL and TESL will be studied. Therefore, the status of literature as a means rather than a result in TEFL and TESL will be brought to light.

Sell (2005) states that literature instructs cultural multiplicity and this may aid fresh generation students to consider cultural assortment satisfactory and a significant element when it comes to the expansion and growth of nations. Chen (2014) additionally adds that collaboration is based on cultural suitability and suppleness for further cultures and populations. Chen (2014) further advances that teaching new literature to language students aids raise their comprehension and consciousness of fresh cultures in addition to their comprehension of dissimilar "living laws".

\section{Literature Review \\ Teaching Literature}

The utilization of literary genre as a method for teaching jointly fundamental language skills (that is to say listening, speaking, reading, and writing) and language fields (that is grammar, vocabulary, and pronunciation) is so common in the domain of learning and teaching English currently. Furthermore, in translation classes, several foreign language educators ask their learners to interpret literary textbooks as tragedy, verse, and novellas into their native language. Because translation offers learners the possibility to exercise the rhetorical, linguistic, semiotics, systematic and eloquent information they have learned in other classes, translation is both like a practical field enfolding listening, speaking, reading, and writing, and like the fifth skill is highlighted in foreign language teaching. In the subsequent part, why foreign language educators utilize literary textbooks in TEFL and TESL and the main motives for choosing appropriate literary manuscripts in TEFL and TESL classrooms are emphasized to make the reader acquainted with the principal motives and reasons for foreign language teachers' employing and choosing literary textbooks.

Sholichach and Purbani (2018) stated the requirement for incorporating literary genres into foreign language programs. They believe that literary textbooks give real examples and affluent resources for language improvement and disposing of fiction dispossesses students of a valuable chance and an incredibly beneficial means to cultivate the language they plan to study most methodically. As supporters of content-based instructing, Bland and Mourão (2017) maintained that, because EFL classrooms possess a pluricultural constitution, the integration of literary genre in the curriculum, as a practical tool for language teaching, is fundamental. 


\section{Motives for Utilizing Literary Textbooks in TEFL and TESL}

In 1990, Collie and Slater stated that four main motives guide a foreign language educator to employ literature in TEFL and TESL classrooms. These are important authentic material, cultural enrichment, language enrichment, and personal involvement.

\section{Helpful Genuine Material}

Literature is an effective device. Mostly, writings of literature are not made for the first reason for teaching a foreign language. A lot of real examples of language in everyday life situations (for example voyage schedules, town maps, documents, brochures, animated films, ads) are embraced in recent advanced classrooms tools. Therefore, in a class situation, students are put through authenticated language examples of daily life situations. Fiction can proceed like a favourable supplement to such tools. In studying literary textbooks, as learners are obliged to manage with language planned for native orators, they grow to be acquainted with a lot of diverse grammatical formulas, oral purposes, and senses.

In 2007, Duff and Maley highlight that instructors can manage with a lot of the challenges that literary textbooks offer if they give a sequence of questions to evaluate the appropriateness of manuscripts for any specific group of students:

Is the topic apt to attract this group?

Is the language level suitable?

Is it the right span for the time offered?

Does it need much cultural background information?

Is it culturally unpleasant in any manner?

Can it be effortlessly used for language learning objectives?

\section{Cultural Fortification}

For a lot of language students, the perfect manner to boost their comprehension of spoken / non-spoken elements of communication in the nation within which that tongue is addresses, a trip or a vacation, is simply not possible. For these students, literary materials, like tales, drama, novellas, etc. aid in comprehending how talking happens in that nation. Even if the world of a novel, drama, or tale is an unreal one, it offers a filled and bright surrounding where personas from various societal and districts milieu can be portrayed. Learners can perceive the manner the personas in these storybooks observe the exterior world (that is to say their ideas, sentiments, practices, rituals, ownerships; what they purchase have faith in, are afraid of, take pleasure; the manner they talk and act in diverse backgrounds). This multi-hued made world can rapidly aid the student to relate to the symbols and concerns that form an authentic community utilizing imaged literacy of the study of signs as elements of communication. Fiction is may be viewed as a supplement to other tools employed to improve the student's comprehension of the nation whose tongue is being taught. Besides, literature puts in a great deal to the student's language rules.

For example, a cultural model in literature is a conventional method to teaching literature that aspires to comprehend and value cultures and thoughts dissimilar from one's own in time and area. Within this model, students have to search and understand the societal, political, scholarly, and historical framework of a particular text.

\section{Language Enhancement}


Fiction gives students a varied choice of personal rhetorical or linguistic pieces. Learners grow to be acquainted with many aspects of the lingua, scanning a considerable and contextualized important part of work. They study the grammar and dialogue meanings of phrases, the range of potential formations, and the diverse ways of linking thoughts, which cultivate and enhance their writing competence. Also, learners become more creative and audacious as they start observing the affluence and range of the foreign language they are attempting to study and start to utilize a number of these abilities themselves. Therefore, they develop their oral and literary skill in the real wealth, genuineness of the authenticated textbooks.

Literature classes, as Mainland (2013) advanced, aid learners locate their voice. In this manner, getting learners to speak in another language and helping them to communicate have a lot in common. He adds that Literature can be used as an instrument instead of an end in instructing English as a foreign or second language.

\section{Individual Taking Apart}

Literature can be helpful in the learning procedure of a language because of the individual interest it cultivates in the reader. As soon as the learner scans a literary textbook, he starts to dwell in the text. Comprehending the senses of rhetorical things or sentences turns into less important than following the advancement of the narrative. The learner grows to be keen to discover what occurs as happenings unfold through the climax; he senses familiarity with some personas and imparts their affecting answers. This fact can have helpful outcomes upon the entire tongue knowledge procedure. At this point, the importance of the choice of a literary textbook corresponding to the requirements, anticipations, and concerns, the learners' rank of language is plain. Within this procedure, he can get rid of the individuality crisis and grow into an outgoing person.

Maley (1989) mentioned several reasons for considering literature are registered as a powerful source in the language learning process as the following:

Universality

Non-triviality

Personal Relevance

Variety

Interest

Economy and Suggestive Power

Ambiguity

Universality

Literature tackles familiar themes to all human beings. It deals with topics that are universal despite their diverse manner of handling. Themes like love, faith, freedom, etc. All these happenings occur to individuals.

\section{Non-triviality}

A lot of other common modes of language instruction contributions are likely to play down textbooks or knowledge. Literature does not make light of or underplay. It concerns topics that are significant to the writer while he notes them down. It can provide authenticity in addition to just "genuine" absorptions. 


\section{Personal Relevance}

Because it copes with thoughts, objects, feelings, and happenings that also comprise an element of the readers' occurrences or that they can go into creatively, they can connect it to their private existences.

\section{Variety}

Literature comprises inside it the entire potential diversities of themes. It is a series of a subject to employ in teaching a foreign language. Within the literature, learners can acquire the language of the economy and finance, of medication and boxing, and the house of worship.

\section{Interest}

Literature copes with subjects and matters which are fundamentally stimulating, as they are parts of the individual happenings, and discuss them in manners intended to hold the interest of the readers.

\section{Economy and Suggestive Power}

The evocative strength is one of the remarkable powers of literature. Still, within its plainest kinds, it calls to surpass what it informs and what it entails. Because it proposes a lot of thoughts with little speech, literature is perfect to produce language conversation. Maximum productivity can frequently be originated from the least effort.

\section{Ambiguity}

Seeing that it is very evocative and clannish, literature talks cleverly diverse denotations to dissimilar individuals. It is uncommon for two learners who read to respond identically to one particular passage. In lessons, this possesses two gains. The primary gain is that every student's understanding contains power within constraints. The subsequent benefit is that a roughly endless stock of interactive conversation is assured because every individual's discernment is not the same.

Not including the earlier listed reasons for utilizing literature in TEFL and TESL, sociolinguistic wealth is one of the main roles of literature. The employment of language varies from one communal band to another. Similarly, it alters from one physical place to another. A person talks differently in diverse communal milieus as airport, school, infirmary, cinema, and concert (that is to say official, familiar, unfussy, unfriendly, close approaches discourse). The language utilized alters from one job to another (that is architects, biologists, and lawyers) employ diverse terms. To place it another way, because literature offers learners a large variety of language ranges as local vernaculars, terminology, slangs, etc., it increases their sociolinguistic skill in the aim tongue. For this reason, integrating literature into TEFL and TESL curriculum as an influential basis for exposing the sociolinguistic features of the aim tongue acquires significance.

\section{Decisive Factors for Choosing Appropriate Literary Work in TEFL/TESL}

Collie and Slater (1990) highlighted that while picking the literary textbooks to be utilized in language lessons, the language educator ought to consider the requirements, inspirations, notices, educational milieu, and language rank of the learners. Nevertheless, what is needed to be allowed for is whether a specific work can expose the type of individual taking 
apart through stimulating the students' notice and bringing about powerful, optimistic responses from the learners. Scanning a literary textbook is expected to contain a durable and beneficial outcome upon the student's sociolinguistic and linguistics information once it is evocative and entertaining. Selecting paperbacks related to the student's everyday existence happenings, feelings, or reveries is of big significance. Besides, tongue intricacy must be measured. Proviso the language of the scholarly work is plain, it can ease the plainness of the scholarly text however may not be in itself the most significant reason. Attention, influence, and significance are as well crucial. Pleasure; an airy perception into matters sensed to be connected to the mind of individual's interests; the enjoyment of meeting a person's ideas or circumstances demonstrated evidently in an artwork; the other, equivalent enjoyment of perceiving those alike ideas, sentiments, sensations, or circumstances portrayed through a fresh prospect: the entire of these are reasons aiding students to tackle the linguistic obstructions which might be thought overly eminent in less connecting items.

There are significant standards that must be measured when picking the text. Hill (1994) claimed that the fundamental conditions to bear in mind when selecting a literary text like the following:

- The requirements and skills of the learners,

- The language and literary level of the text,

- The volume of background knowledge needed for a real approval of the material.

-The lexis and sentence organization of the short story to be examined must be appropriate to the level of the learners.

Short stories with archaic language, slang, foreign words, allusions, or language that imitates the speech of a particular locality, uneducated people, or foreigners must be avoided. Similarly, very long sentences are difficult for students to understand. As students will not understand these sentences and words, they will get bored and not read the work.

\section{Literature and the Instruction of the Four Skills}

Literature performs a significant task in instructing the four fundamental skills (i.e. listening, speaking, reading, and writing). Yet, while employing literature in EFL and ESL classes, skills must not be instructed in seclusion but an incorporated manner. Educators must attempt to teach listening, speaking, reading, and writing like a connected section of spoken and printed language utilization, like an element of the means for producing jointly denotative and interchange sense, not just like a feature of the spoken and printed making of terms and sentences.

\section{Reading Skill and Literature}

Stern (1991) pointed out that English language teachers must embrace an energetic student-centred method for a great understanding of a literary text. In the reading classroom, a conversation starts at the literal point with straight queries of information about scenery, personas, and intrigue that may be replied to through explicit indication to the text. When learners get exact comprehension, they shift to the presumed rank, in which they should build suppositions and understandings regarding the personas, scenery, and topic, and in which they create the author's opinion. As soon as students grasp a literary choice at the factual and 
presumed ranks, they are set to produce a joint task. To be precise they communicate their assessments of the text and their responses to the work - to its personas, its topic(s), and the author's opinion. Besides, this is the appropriate moment for them to communicate their feedbacks to the work's likely educational concerns and subjects. The next rank, the individual/assessment level inspires learners to consider creatively regarding the text and incites their issue-resolving competencies. Conversation origination from such queries may be the basis for spoken and on paper exercises.

Aminuddin (2002) added that literary works are a way out to make changes and planting the character of students. Literature has great potential in bringing society toward change, including changes in a person's character.

\section{Speaking Skill and Literature}

Literature can be an influential and inspiring basis for writing skills in EFL and ESL classrooms, jointly like a style and like the topic. Literature like a style happens once students' writing skill grows to very much resemble the initial text or emulates its substance, subject matter, orderliness, and /or method. Nevertheless, as soon as students' writing skill shows initial thought as elucidation or scrutiny, or once it comes out of, or is ingeniously inspired by, the scanning, literature operates as a theme. Literature takes in a vast range of topics to put in writing concerning directed, unbound, cautious and further sorts of writing.

Though the application of genuine literature is through reading yet according to Day and Bamford (1998) as mentioned in Thomas' (2006) work, he reconsiders many studies of general reading curriculums; these examinations reveal that learners who read vastly not just enhance their reading skills and writing skills, but as well their vocabulary, and also their listening and speaking proficiencies so that it can be perceived that it is suitable to employ genuine literature in instructing speaking skills. Phat (2013) stated that learning literature can cultivate the students' interpretations and improve their English and communication proficiency.

\section{Literature like a Style for Writing}

Three major types of writing can be founded on literature like a style:

\section{Contained Writing}

It is employed chiefly in commencement-class writing usually needs rewriting parts in random manners to do particular semantic formations. For example, learners can be correspondents performing a live news bulletin, or they can rewrite another character passage into the initial character from a character's opinion.

\section{Directed Writing}

This exercise is compatible with medium classes in EFL and ESL classrooms. Learners reply to a sequence of queries or entire phrases which, once constructed, restate or recap the genre. In certain situations, learners finish the activity following obtaining the primary few phrases or the subject phrase of a synopsis, reword, or portrayal. Directed writing activities, particularly at the factual point, allow learners to understand the text. The replica method is very helpful in this matter. 
Replicating the Replica

Stern (1991) explained that this exercise includes practices as rewording, synopsis, and adjustments. These methods are very helpful in EFL and ESL writing activities. In rewording, learners need to utilize their expressions to put another way the ideas which they heard about or read. Because rewording matches with the learners' attempting to understand the verse, it is a noticeably helpful means with poems. Synopsis work comes off with genuine tales and drama, in which happenings, in general, ensure a sequential organization and possess specific constituents as intrigue, scenery, and persona to direct learner writing. Alteration needs rewriting writing style literature into a conversation, rewriting a drama or an event into a story. This exercise permits learners to be conscious of the adaptations between printed and oral English.

\section{Literature like a Topic for Writing}

Spack (1985) observed that locating suitable tools for their writing lessons is occasionally difficult for structure teachers given that writing does not possess its topic. One profit of holding fiction like the reading matter of an organization course is that the readings turn out to be the topic for organizations. In an organization lesson whose reading composition is literature, learners make a deduction, express their thoughts, and stare densely at a passage for proof to sustain sweeping statements. Therefore, they are trained to contemplate ingeniously, liberally, and significantly. Such exercises aid students in further lessons that need a rational way of thinking, free thoughts, and thorough study of the work.

Two main types of writing are founded on fiction topics: writing "concerning or as regards" fiction, and writing "owing to" fiction. These types are appropriate and helpful for EFL and ESL classes.

\section{Writing “Concerning or as Regards" Literature}

Writing "concerning or as regards literature" includes the conventional tasks, on paper answers to queries, section writing, classroom dissertation, and home organizations where learners examine the text or where they contemplate literary tools and methods. Writing "concerning or as regards literature" can happen before learners start to scan a text. The educators usually talk about its topic or an issue it increases, and the learners write about it in connection to their existing event. This exercise increases their attention in the text and prepares them to be prepared for scanning and jot down on it. Nearly all writing tasks completed in addition to following the reading, yet, originate from classroom conversation. Activities are given in different manners, like queries to be responded to, declarations to be discussed, or themes to be developed, conversation bands to be created.

\section{Writing “Beyond" Literature}

It signifies employing a literary text like a launchpad for an organization - imaginative tasks cultivated about intrigue, personas, scenery, topic, and rhetorical language. There are diverse types of copying out of fiction, like writing the text, converting the text, play-stimulated writing and a message dispatched to further persona, etc.

Inserting in the work includes writing creative consequences, or, in play "standing in" settings for backstage deeds which are just brought up in the conversation.

Converting the work: Learners can imagine their ends by contrasting the writer's 
conclusion to their personal. Tales can be written entirety or division from the opinion of a persona vs. a third character storyteller or of a different persona.

Play-stimulated writing: It is probable to originate play-stimulated writing tasks from dramas, tales, narratives, and occasionally poems. The learner moves into the awareness of a persona and jots down on that personas stances and sentiments.

A message dispatched to further persona: The learner can jot down a letter to one of the personas, where the student provides the persona with his/ her recommendation on the manner to surmount a specific difficulty or circumstance.

\section{Speaking, Listening Skills and Literature}

Although it is mostly connected with reading and writing, learning fiction in EFL and ESL classrooms can perform a similarly significant function in instructing jointly listening and speaking. Spoken scanning, adaptation, ad-libbing, performing a role, rebuilding, and band tasks can focus on the production of fiction.

\section{Spoken Reading}

EFL and ESL teachers can render articulation and listening comprehension attentiongrabbing, inspiring at the higher ranks, showing a tape or film of literary production, or scanning fiction loudly themselves. Making learners read fiction loudly adds to advancing listening in addition to speaking skills. Furthermore, it guides as well as enhancing articulation. Articulation can be the focal point before, throughout, and following the reading.

\section{Play}

Literature-founded theatrical exercises are very important for EFL and ESL classrooms. These activities ease and speed up the progress of the students' oral skills because these exercises stimulate learners to obtain a better understanding of a work's intrigue and a more profound grasp and consciousness of the work personae. Even if the drama in EFL and ESL can take up many types such as staging, performance, and ad-libbing.

\section{Staging}

Staging needs classroom presentation of screenplay items. Learners can create their writings for tales or parts of narratives, modifying them as nearly as possible to the real work. Founded on the narrative, they ought to deduce what the personae would state and the way they would state it. Writings by learners are as well possible with drama. Poems including one or more characters may as well be written by learners. Learners must carefully scan appointed parts of conversation before and can respond to queries on personae and intrigue. They must point out words, phrases, or conversations they do not grasp and terms they cannot articulate. After that learners practice the scene with their classmates. Even if students do not learn it by heart, they read it adequately to make eye contact and state their sentences with sense and emotion. Furthermore, they talk about semiotic features of dramatization (that is to say expressions of the face, gesticulation, and corporeal features.) Finally, the staging is displayed before the lesson.

\section{Performance and Ad-libbing}

Both performance and ad-libbing can be cultivated about the personae, intrigue, and 
subjects of a literary text. Ad-libbing is a further methodical exercise, that is to say, a performance that does not have a script. There is a particular intrigue with a commencement, centre, and conclusion in ad-libbing. Nevertheless, in-role performance, learners imagine personae from the scanned text and take part in a speaking exercise except an ad-libbing, like a dialogue or team conversation.

\section{Team Exercises}

Stern (1991) maintained that making every learner in charge of information and thoughts to be added and talked about, and team exercise rouse whole partaking. All learners are engaged and the partaking is multidirectional. While TEFL/ TESL utilizing fiction, certain team exercises employed in EFL/ ESL classes are common class conversation, tiny-team work, team conversations, and arguments. All of these team exercises advance both the speaking skills of the learners and provide significance to pronunciation rehearsal. Educators show pronunciation mistakes of the learners throughout the deeds of these exercises to rectify such errors.

\section{Advantages of Diverse Types of Literature to Language}

\section{Advantages of Employing Poems to EFL/ESL}

- Poems can lead to the learning and teaching of listening, speaking, reading, and writing. It is a symbol (i.e. it is the most important link between learning and poem). Since most poems deliberately or unintentionally utilize metaphor-like one of their first means, poems give an important learning procedure. No less than two learning advantages can be originating from learning poems: The approval of the writer's make-up process, which learners obtain through learning poetry by components

- Growing sensitivity for poetry and findings can later develop into a more profound notice and better diagnostic skill.

Furthermore, Saraç (2003) presented the educational advantages of poems in this way:

- offers learners a dissimilar opinion towards language utilization through surpassing the usual uses and norms of language rules, sentence structure, and words,

- activates inert learners because of being exposed to examinations and diverse understandings,

- calls to mind emotions and ideas in spirit and soul,

- makes learners acquainted with figures of speech because of being an element of everyday language utilization.

Sage (1987) demonstrated that the language used in poems call to mind and praise particular characteristics of existence and provide learners with emotions. It is specifically lyric poetry that is founded on sentiments and offers further expressive advantages. Poems are among the most efficient and influential aerials of civilization. According to Sage, poetry includes a lot of educational components that are references, words, expressions, a pitch that are difficult to interpret in a different tongue.

\section{Advantages of Utilizing Novellas in TEFL/ TESL}

Novellas are an absolute reserve for scrutinizing not just language but existence itself. In stories, characters imitate the entire authentic and representative deeds persons do in their everyday life and act so in a range of lists and pitches (Sage, 1987). The universe of narratives jointly reflects and lights up human existence. The insertion of a novella in the TEFL and TESL 
program gives the subsequent learning advantages,

- Eases the reading exercise owing to being plain and brief in contrast to the further literary types,

- develops the superior rank of the readers' opinions concerning diverse civilizations and dissimilar types of person,

- offers more imaginative and defiant passages which need individual searching hold with previous information for superior rank learners,

- encourages students to read owing to being a real means,

- gives a universe of marvels and a universe of secrecy,

- Offers learners the opportunity to utilize their imagination,

- advances analytical thought abilities,

- helps the teacher in TEFL and TESL classrooms that is to say works like a useful tool in achieving educational information of the chosen society,

- frees and liberates learners and renders them more at ease with themselves,

- aids learners from different milieus to converse with others due to its worldwide talking,

- aids learner to surpass the superficial significance and plunge into essential significances,

- functions as an ideal means to aid learners to grasp their ranks in addition to passing on this obtained information to their universe.

In short, the employment of a novella appears to be a very useful method in current TEFL and TESL. Because it is brief, it renders the students' reading exercise and the teacher's reporting more effortless. In other words, universal learners have gone through anecdotes and can connect them. Furthermore, the novella, as other kinds of fiction, renders involvement to the growth of cognitive critical skills through carrying the entire personality to stand on a packed in the story of a circumstance in one location and instant (Sage, 1987).

\section{Advantages of Employing Play to EFL/ ESL}

Employing ply in EFL/ ESL classes is a good supply for language teachers. It is through the utilization of play that students grow to be acquainted with sentence organizations in situations and become familiar with the language to communicate, manage and update. The employment of drama cultivates the students' consciousness towards the aimed tongue and civilization. In this background, the employment of play like an instrument instead of a purpose obtains significance in TEFL/ TESL. However, one apparent hazard is that educational obligation should be strictly avoided because it causes the deficit of tongue ego and innate tongue characteristics in a lot of situations. Because of this, the new tongue and the milieu of the play must combine into a language teaching procedure with ultimate notice, significance, and pleasure. Students must utilize drama to support their understanding of existence happenings, consider specific situations and add up their universe in a more profound manner (Saricoban, 2004). The instructive advantages of play are in this way:

- rouses the creativity and encourages inspired thoughts,

- cultivates analytical thought abilities,

- encourages language advancement, 
- intensifies efficient listening abilities,

- reinforces understanding and knowledge preservation through entailing the sanity like a connected fraction of the learning procedure,

- augments compassion and responsiveness to others,

- cultivates classmates esteem and team support,

- strengthens constructive self-perception,

- gives instructors a new viewpoint on instruction (Lenore, 1993).

Additional instructive advantages of employing play in TEFL/ TESL classrooms can be listed in this way:

- causing realism into the lesson,

- putting the students through the aimed society in addition to the communal issues a culture may be experiencing,

- augmenting inspiration, ingenuity, inventiveness, resourcefulness creativeness, vision, and inspection of ethical approaches, at the same time as cultivating interaction abilities and enjoyment of fiction,

- aiding learners enhance their level of skill concerning their responsive and creative competencies,

- offering a dense foundation for the students to link the hole between their responsive and creative abilities,

- giving learners the gap and time to cultivate fresh thoughts in different milieus (Mengü, 2002).

To put it differently, the utilization of play appears to be an efficient method in current interaction-founded, learner-centred TEFL/ TESL. Because it is authentic material, it aids learners to encourage their understanding of the spoken / non-spoken features of the aimed tongue they are attempting to master. Specifically, instructors, who desire to render foreign language learning brighter, more exciting, can employ play in their TEFL/ TESL classrooms. Because drama is the rebuilding of communal happenings, learners enhance their character and codes of performance. Therefore, they can attain a more significant and genuine education from which learners can obtain a big degree and level.

\section{Advantages of Employing Narrative to TEFL/ TESL}

The utilization of a narrative is a helpful method regarding mastering not just syntax technique but as well as existence corresponding to the aimed tongue. In a narrative, personae mirror what persons do in everyday life. Narratives not just exhibit but also inform an individual's life. Employing a narrative in TEFL/ TESL classrooms gives the subsequent enlightening advantages (Arığul, 2001),

- cultivates the superior rank learner' information concerning diverse societies and dissimilar teams of persons,

- augments learners' interest to read because of being a real material,

- provides authentic sceneries,

- offers learners the chance to utilize their imagination,

- enhances analytical thought competencies,

- leads for instructing the aimed tongue culture, 
- permits learners to exceed what is on paper and plunge into what is intended, In 1998, Helton, Asamani, and Thomas stated the instructive advantages of narratives in this way:

- rouses their creativity,

- aids learners to recognize the feelings of the personae to be able to learn the manner others deal with circumstances and issues like their personal happenings,

- aids students to master the abilities which will permit them to obtain knowledge, procedure this information, spot issues, plan substitutes, and reach efficient resolutions and answers,

- cultivates spoken and on paper language competencies,

- operates as a launchpad for a big number of all knowledge and analytical thoughts exercises stimulated within basic comprehension,

- offers an exclusive method of instructing reading through making learners engaged and stimulated regarding the scanning procedure,

- motivates learners to become constant learners.

Once choosing a narrative to be employed in the TEFL/ TESL classrooms, the foreign language instructor should concentrate if the story owns a fascinating account that will be exciting to the whole classroom. Topics and sceneries enthralling their creativity and searching the individual state must be involved in the type of picked accounts. The narrative must possess an influential intrigue and inspire correctly defined, outstanding personae. The matter of the story must be appropriate to students' analytic and affecting points. Particular topics and notions being cultivated in the classroom just as well be embraced in the story.

While evaluating students' understanding, teachers can utilize story exercises to cultivate students' sub-competencies on paper as punctuation, syntax, script, and spelling. Dissertation exercises, which are given by teachers, aid learners to slowly enhance their abilities in writing and arranging information into articles with satisfactory grammar. The exercises are composed of not just information-founded questions operating like a foundation of assessing understanding but also unlimited queries cultivating analytical thoughts skills. The unrestricted questions allow learners to forecast conclusions, do distinctions and dissimilarities, and extract endings. Classroom conversations of every narrative happening must include the main thought and sustaining facts, entailing what, where, when, who, where, and how. Information of a range of social problems like sexual aggression and kidnapping that are a connected fraction of the intrigue can cause motivating discussion. Besides, debates ease terms of growth (Helton, 1998).

Overall, the utilization of narrative is a very helpful method in current TEFL and TESL classrooms. If picked meticulously, employing a story renders the students' reading class inspiring, exciting and amusing. Even if many learners notice reading a story on paper in an aimed tongue tough, dull, and not stirring, a story is a very efficient manner of constructing terms and cultivating reading understanding abilities. It is by employing scanning that learners enlarge their prospects, become acquainted with different societies, and consequently extend their oral skills, learning how to see the universe from dissimilar viewpoints. The consequence will be the owner of analytical writing and thoughts.

Literature can render the teaching of English more interesting if teachers are well-trained 
and equipped with the appropriate materials. Teaching English through literature aids learners to talk about grammar and sentences interactively. Teachers can use amusing subjects to stimulate students to convey their opinion and, present controversial themes and more in profound subjects, as Translations.

Moreover, literature proves to aid in promoting the students' fundamental language learning occasions and growing their language knowledge. In addition, it sustains encouraging their intellectual development by perceiving and liking the abundant literary universe that surrounds them.

\section{Conclusion}

Fiction performs a significant role in the TEFL / TESL classes of a lot of non-English speaking nations. Nevertheless, some issues are faced by foreign language teachers in the zone of instructing English utilizing fiction. Among these problems, not many suitable materials are employed by foreign language instructors in a language lesson. Besides, there is a deficiency of training in the zone of fiction lessons in TEFL / TESL curriculums. Moreover, no definite targets are describing the position of literature in TEFL / TESL. Many teachers attempt to comprise fiction in their curriculum, yet need the training and preparation in that area. The teacher has a significant function in instructing English utilizing literature. Teachers must settle on the objective of language instruction regarding the requirements and prospects of the learners. By providing a survey or interrogating the learners orally, the instructor can establish the goal and the targets of the language instruction. In addition, teachers must choose a suitable language lessons technique, instruction methods, and class exercises. Additionally, the teacher must pick the literary text applicable to the target and the goals of his lessons. When choosing literary work to be employed in language classes, the student's language skills, notices, gender, and age must be considered so as not to tire learners with unsuitable resources. At basic levels, for instance, learners must be provided easy or particularly on paper accounts. At superior ranks, nevertheless, learners are offer fiction in its primary shape to be able to cultivate their literary skill in the aimed tongue. In other words, learners study almost the everyday utilization of the aimed language in the literary work and meet diverse types of literature like poetry, novellas and play at superior ranks. By detecting how characters in drama or a novella utilize figures of speech, like symbols, allegory, students learn how to write English more plainly, imaginatively, and strongly.

Literature aid students to obtain a native-like ability in English, convey their thoughts fluently, study the aspects of current English, study how the English linguistic method is employed for communication, and observe how fluent sayings are employed. Thanks to these benefits, students learn to talk plainly and succinctly and become more skilled in English, in addition to becoming imaginative and analytical. Fiction can unlock spheres of opportunity, permitting learners to query, understand, link, and investigate. Overall, literature offers learners a very affluent basis of authentic material on top of a large variety of roles. If learners can obtain admission to this material through cultivating literary skills, they will be able to efficiently attribute the language at an advanced rank. Students with spoken / syntax cleverness, the foreign language instructor's employing fiction in TEFL / TESL classes works for producing a very inspiring, entertaining, and energetic class. Literature is not just an instrument for growing on paper and spoken competencies of the learners in the aimed tongue but is also a casement unlocking into the civilization of the aimed language, developing an educational skill in learners. 


\section{About the Author:}

Dr. Nadia HAMIMED, Algeria, 22nd October 1984. She is a lecturer at the University of Tlemcen, Faculty of Technology, Department of Civil Engineering. She has a PhD in Comparative Literature, 2020, University of Sidi Bel Abbes, Algeria. She has more than 2 publications in international peer-reviewed journals. She wrote in two international books. She has more than 5 international communications. She is interested in didactics, women writing, culture, and comparative literature. 0000-0002-6379-8465

\section{References}

Aminuddin, L. M. (2002). [Pengantar apresiasi karya sastra]. Bandung: Sinar Baru.

Arıoğul, S. (2001). The Teaching of Reading through Short Stories in Advanced Classes, (Unpublished Master's Thesis). Hacattepe University, Ankara.

Bland, J., \& Mourao, S. (2017). The Shapeshifting Nature of Children's Literature for ELT. Children Literature in English Language Education Journal, 3(2), 24-36.

Chen, M. L. (2014). Teaching English as a foreign language through literature. Theory and Practice in Language Studies, 4(2), 232-236.

Collie, J., \& Slater, S. (1990). Literature in the Language Classroom: A Resource Book of Ideas and Activities. Cambridge: Cambridge University Press.

Day, R. R., \& Bamford, J. (1998). Extensive Reading in the Second Language Classroom. Cambridge: Cambridge University Press.

Duff, A. \& Maley, A. (2007). Literature (Resource Books for Teachers). Oxford University Press.

Helton, C.A., Asamani, J., \& Thomas, E.D. (1998). A 'Novel' Approach to the Teaching of Reading. Tennessee State: Tennessee State University.

Hill, J. (1994). Using literature in language teaching. London: Macmillan.

Lenore, K.L. (1993). The Creative Classroom A Guide for Using Creative Drama in Classroom. U.S.A.: Elsevier, Inc.

Mainland, C. (2013). Teaching Literature like a Foreign Language; or, What I Learned When I Switched Departments. Pedagogy, 13(1), 145-148.

Maley, A. (1989). Down from the Pedestal: Literature as Resource in Literature and the Learner: Methodological Approaches. Cambridge: Modern English Publications.

Mengü, H. I. (2002). A Suggested Syllabus for the Drama Teaching Course in ELT Departments, (Unpublished Master's Thesis). Hacettepe University, Ankara.

Phat, C.H. (2013). The Implementation of Literature in Teaching Speaking for Advanced Students. Viet Nam. The Ho Chi Minh University of Education.

Sage, H. (1987). Incorporating Literature in ESL Instruction. New Jersey: Prentice-Hall, Inc.

Saraç, S. (2003). A Suggested Syllabus for the Teaching of Poetry Course in ELT Departments of Turkey, (Unpublished Master's Thesis). Hacettepe University, Ankara.

Saricoban, A. (2004). Using Drama in Teaching Turkish as a Foreign Language in Eurasian. Journal of Educational Research, 19(4), 703-721.

Sell, J. (2005). Why Teach Literature in Foreign Language Classroom? Encuentro, 15, 86-93.

Sholichah, IR, \& Purbani, W. (2018). Fostering Language Skills Development through Fairy Tales: A Literature Study. Proceedings of the International Conference of Communication Science Research (ICCSR). Available at https://www.atlantispress.com/proceedings/iccsr-18/25904631 
Sholichah, IR, \& Purbani, W. (2018). Fostering Language Skills Development through Fairy Tales: A Literature Study. Proceedings of the International Conference of Communication Science Research (ICCSR). Available at https://www.atlantispress.com/proceedings/iccsr-18/25904631 Stern, S. (1991). An Integrated Approach to Literature in ESL / EFL in Teaching English as a Second or Foreign Language. Boston: Heinle and Heinle Publishers.

Thomas, H. K. (2006). Developing Presentation Skill by Using Authentic Literature. The Internet TESL Journal New York, XII(11). Available at http://iteslj.org/Lessons/ThomasPresentationSkills.html 